This item was submitted to Loughborough's Research Repository by the author.

Items in Figshare are protected by copyright, with all rights reserved, unless otherwise indicated.

\title{
'They are too young to understand health' a researchers reflexive account of researching with under fives
}

\section{PLEASE CITE THE PUBLISHED VERSION}

http://dx.doi.org/10.1080/13573322.2017.1376639

\section{PUBLISHER}

(c) Taylor \& Francis

\section{VERSION}

AM (Accepted Manuscript)

\section{PUBLISHER STATEMENT}

This work is made available according to the conditions of the Creative Commons Attribution-NonCommercialNoDerivatives 4.0 International (CC BY-NC-ND 4.0) licence. Full details of this licence are available at: https://creativecommons.org/licenses/by-nc-nd/4.0/

\section{LICENCE}

CC BY-NC-ND 4.0

\section{REPOSITORY RECORD}

Stirrup, Julie. 2019. "'they Are Too Young to Understand Health' a Researchers Reflexive Account of Researching with Under Fives". figshare. https://hdl.handle.net/2134/26425. 
'They are too young to understand health'

A researchers reflexive account of researching with under fives

Julie Stirrup School of Sport, Exercise and Health Sciences, Loughborough University, UK Corresponding author email: j.l.stirrup@lboro.ac.uk 


\begin{abstract}
Qualitative research is an inherently complex landscape which continually presents researchers with difficult, ethically challenging dilemmas. This paper foregrounds some of those challenges, experienced during a qualitative research study which focused on preschool children's opportunities to access different forms of play in early year education settings and the impact of this on their learner identities and understandings of health. Specifically, the paper focuses on the challenges faced by the researcher when addressing issues of access, including dealing with gatekeepers and the influence they potentially have upon the meaning and authenticity of the data collected. The analyses explore how well the three methods (interviews, structured activities and observations) employed to ensure that the voices of young children, rather than those of gatekeepers and other adults, were captured by the research process, reflected their views, and recognized them as active, embodied, social agents.
\end{abstract}

Keywords: Health, play, methodology, early years education, voice 


\section{Introduction}

This paper details the research methods employed during a three-year study investigating children's understandings of health, embodiment and their opportunity to access different forms of play in Early Year Education (EYE) settings in England (Stirrup, 2014). It highlights the challenges and possibilities of conducting research with very young children, in this case age three - four, aiming to encourage and assist other researchers to include young children in qualitative research particularly that related to physical education, health and embodiment. Embodiment here refers to the processes by which we consciously and subconsciously develop a unique cultural lens to make sense of our being and becoming in the world. This lens is comprised of values, attitudes, assumptions and beliefs acquired within the family, community and wider experiences (e.g., in schools, religious affiliations, club environments). The processes of embodiment is particularly important in this discussion given the physical nature of health and how young children learn - essentially through their bodies via play. I suggest that Bernstein's concepts, particularly the 'pedagogic device' (PD) go some way toward providing a language to discuss pedagogic consciousness, but not completely its embodiment. For this, we need also look to the 'corporeal device' (CD) (Evans et al 2009) as means of better focusing the relationships between the body, pedagogy and society (expressed initially as PD/CD intersections). Adopting the view that embodiment refers to the way in which policies (when recontextualised as curriculum, pedagogy and assessment) both affect and effect a child's sense of being somebody in the social world, in relation to time and space (Evans and Davies, 2011). This paper also recognises the work of Pink (2011) and assumes the fluid nature of embodiment and argues that enactment, the process of locating the body within time, space and place, is equally important to consider. Pink suggests that shifting from a theory of embodiment to one of emplacement allows us to see the body in relation to other bodies and other representations, rather than as a singular (isolated) identity. Others, e.g., Quennerstedt et al (2011) have used John Dewey's concept of transaction to explore embodiment within physical education. They are not however able to show how or why transactions are shaped in particular ways. In Evans et al (2009) view, processes of embodiment, emplacement and enactment (see Braun et al 2010; Braun et al 2011; Maguire, Hoskins, Ball and Braun, 2011) are shaped and formed in a never-ending (interminable) cycle expressing the connections between the PD/CD. The CD PD facilitates the investigation of embodiment in EYE; centring agency, materiality and a 'bottom up approach' involving exploration of the perspectives and predispositions children bring into the EYE context. The PD CD foregrounds the principles which regulate teaching and learning. At the intersection of the $\mathrm{PD} \sim \mathrm{CD}$, research questions around the role gender, class and culture play in children's early years learning opportunities and how EYE recontextualization of health, may contribute to young children's understandings of themselves and their corporeality.

Traditionally, children have viewed as part of the larger structure of the family or school and researchers have studied children, focusing almost exclusively on the responsibilities of adults (de Winter, Baeveldt and Kooistra, 1999; Sandbaek, 1999). However, over the last decade a body of literature has emerged which has brought to the fore a range of ethical, 
methodological and epistemological concerns relating to researching children's worlds (Christensen and James, 2008). Recent literature has emphasised the virtues of designing research projects that are 'by' and 'with' rather than 'on' children (James and Pout, 2015). In keeping with this, within early childhood research, there has been a growth of studies that have placed centre stage the views and experiences of young children. Although much of this work has focused on methodological reflections, common among it is the desire to understand the everyday experiences of children in contexts which are familiar to them. Literature addressing EYE research (e.g., Brooker 2002; Dockett and Perry, 2005; Clark, Kjorholt and Moss 2005; Alderson, 2008; Evilly, 2015) has emphasised the use of methods that enable the researcher to listen to the voices of children and co create knowledge and meaning. To this end, I adopted the mosaic approach (Clark and Moss, 2001); a multi method means of investigation in which photos, tours and maps are combined with talking and observation to gain a deeper understanding of children's perspectives. The mosaic approach to researching with young children sees children as experts in their own lives and whilst it uses various methods, including visual imagery, to collect data, it is also focused fundamentally on listening to the child (Clark and Moss, 2005). This emphasis on listening is critically important because it is meant to ensure that the child's perspective is not misinterpreted or undervalued. Following Clark and Moss's (2001) mosaic approach, several data collection methods were employed, including visual methods, a nursery tour, poster making tasks and interviews to engage and retain children's interest. However, notwithstanding adherence to the abovementioned recommendations for researching young children and giving them voice, there were times when the children simply did not want to talk, when it was difficult to keep them on task and they struggled to verbally express their thoughts and ideas. This raised critical issues of interpretation around meaning and authenticity. There were also times when practitioners wanted to determine or substitute the children's voices for their own. How, then, does the researcher respond to and sensitively deal with challenges of this nature?

\section{The Settings}

The field work for the research was carried out in three EYE settings; all names used within this paper are pseudonyms to protect the names and identities of the EYE settings and participants. Busy Buzzy Bees (BBB) is a publicly (Government) funded early years' provider located in a large Midlands town. It provides sixty childcare places for children aged three months to five years old, it is predominately made up of children from a white British background and is commonly utilised by staff and/or students at the local university college. Housed in three mobile classroom units, the setting consists of one unit, divided up into four separate sections; one for each age group (age three months-one year, two-three and threefour), with each 'section' catering for up to fifteen children supervised by two or three practitioners at any one time. The other two units were mostly used as office space. The outdoor facilities consist of a large playground, which each group uses at different times of the day. As many of its children are from professional middle-class families it provided stark contrast to the families who use 'Little People' and 'Little Stars'. 
Little People $(L P)$ is located within a large housing estate on the outskirts of a large town within the Midlands area. It serves the local community, providing childcare for children aged three to five years old, predominantly of White British ethnicity. The setting has two rooms dedicated to three-four-year olds, one for children whose parents paid for their fulltime care and the other for those who only attended for their entitlement of fifteen hours Government funded 'free care' per week ${ }^{\mathrm{i}}$. It was this room, catering for those children who attended nursery for their fifteen free hours, which was the focus of the research. The room caters for up to twenty-five children, supervised by three to four practitioners. Serving a working-class area, this setting facilitated exploration of the opportunities available to working class children to access EYE and their experiences of that provision.

Little Stars (LS), located within a market town in England, caters for children of many ethnic groups (but mainly Bangladeshi families) within the community. This setting was selected because of its cultural diversity. Approximately eighty per cent of the children on roll were from ethnic minorities, of whom $45 \%$ spoke English as an additional language. It occupied three large rooms in one building, offering two daily three-hour childcare sessions for threefour-year olds, catering for up to forty children at any one time, supervised by four-five practitioners.

\section{First considerations}

In attempting to understand the complex world of pre-school children and the seemingly 'unstructured' play environments of nursery I needed research tools which would allow me to both register and explore the multiple, complex, often contradictory, voices of my research participants. I therefore, choose to adopt a critical ethnographic approach to my research. Critical ethnography aims to explore power relationships through sustained involvement in the research setting and as Madison (2005) suggests, can often involve differences in culture, social class, gender and ethnicity. In opting to carry out ethnography, I looked to the work of Willis (1977) and his examination of working class boys' counterculture and social class reproduction for guidance. Willis argues that to understand what is happening in a setting, a researcher must attend to the 'logic of living' to understand the 'social creativity', or in other words the researcher must spend time becoming familiar with the social spaces of the research setting. Furthermore, to gain sophisticated cultural understanding, we must contextualise the research within wider societal hierarchies. Several other critical ethnographies (e.g. Fine, 1991; Hills, 2006; Kincheloe, 2007;), have also explored the complexity of identity focused on one aspect or in some cases the intersectionality between culture, gender, social class etc. In following these critical ethnographies, I adopted a critical ethnographic methodology to provide a deep and nuanced account of my experiences in three EYE settings and to directly attend to the ongoing complex social hierarchies in 'pre' formal education.

In seeking to address issues of equity, opportunity and access to physical activity in EYE, I spent 10 months in each of the three settings, spending 3-4 hours a week in each setting. Acknowledging the need to familiarise myself with the research setting, it could be argued that 3 hours per week is not fully immersing one's self in the setting. However, this was the 
amount of access I was granted and in two of the three settings (LP and LS), children only spent 3 hours of their daily lives in the EYE setting. During my time in each of the three settings, I adopted four key methods: building relationships; informal conversations; observations and; activity based tasks.

\section{Building Relationships}

The insider/outsider dichotomy that Hammersley (1992) and Tedlock (2000) talk about, for me became less important than building relationships and gaining the trust of the children, rather than gaining an 'insider status' to gain 'authentic' accounts. Therefore, to build these relationships, I spent time initially engaging with children in their daily EYE activities, for example, joining in with 'Gathering' and 'Storytime' time, building towers and playing doctors with them etc. By forming these relationships in the first few weeks, I hoped to mitigate any age and cultural barriers there might be.

\section{Informal Conversations}

Semi structured or structured interviews, are a popular method of data collection within qualitative research, and the former were utilised once with practitioners using a Dictaphone. However, most of the data was collected via informal conversations which happened during play time with either practitioners or the children. I never attempted to conduct formal interviews with the child participants as I felt such a formal format of structured questions etc might be uncomfortable and potentially threatening for such young children. Several researchers including Oakley (1981) and Clandini and Connelly (2000) share this view, that there may be potential power issues with interviews due to the interviewer - interviewee hierarchy.

Throughout my time in the EYE settings, children chose to speak to me at various times and for various lengths of time, depending on a range of factors, including, their willingness to participate, level of interest and attention span. During these conversations, I chose to ask the children, questions on health and play because after trialling more formal 'sit down' interviews at Busy Buzzy Bees I found that the children were happier to engage and talk to me (often on the move from one activity to the next) and always on their terms. These informal conversations, were recorded in my note book and formed part of my 'field notes' along with my observations. As Lancaster and Kirby (2014) suggest, children are active in the construction of their social lives and for me this meant allowing them to initiate when conversations took place. Some of the questions I asked included: what does healthy mean to you? Is it important to be healthy? Do you think being physically active is good? What physical activity do you do at nursery? What do you do outside nursery? Follow up questions and pictures were used to unpick children's understandings of health and physical activity.

Children experience learning and achieve 'success' in terms of being seen as 'able' by practitioners (or not as the case might be) not just 'intellectually' or cognitively, but through their bodies' actions and those of significant others (peers, family, EYE practitioners) in situ. Historically habituated, embodied dispositions and propensities that individuals bring to social settings consciously and unconsciously in part, regulate behaviours within them. These 
dispositions were evident in the answers children gave during interviews, and were reflective of wider societal health discourses. For example, for most of the children across the three settings, thinner people were viewed as healthy, running was better than sitting down and fruit was said to be healthier than crisps, chocolate or doughnuts. These responses raise issues about researching the children's agency - were they acting and responding individually or were they responding based on what parents believed or because it is how they felt they should respond? Did adopting the child centred mosaic approach allow me to access children's agency or were there still barriers? As Hemming and Madge (2011) have argued children often reconfigure their understandings by drawing on the knowledge shared by significant others (parents, family, EYE practitioners) and their agency is therefore, how they display and express in this case their 'received' understandings of health. For example, Clara's agency and understanding of health is expressed through her association of bananas, health and muscles.

\section{Observations}

My time in each of the settings gave me greater context and insight into the daily workings of EYE settings and children's lived experiences within them. During my time in the settings, I was aware that both children and practitioners were aware of my presence and I in turn was aware of this when interacting with them. I was careful not to chat with children during 'Gathering' or 'Storytime', not to disrupt or engage with children when being spoken to by the practitioner and be relaxed and unobtrusive when engaging with practitioners so they did not feel like I was judging or critiquing them. Observation was the initial and most useful method of data collection across the settings. On a weekly basis, I observed the children in each setting for a three/four-hour period, during my observations, I took what I refer to as 'field notes', recording what I saw happen and some conversations I heard, in my notebook and these became important pieces of evidence and often starting points for informal conversations.

EYE settings are vibrant, busy contexts within which to conduct research and as such, the question of what to observe became important. Observation involves focusing on the many actions occurring all at the same time; participants' movements, subtle eavesdropping, asking questions (Taylor and Bogdan, 1975) and in the EYE context responding to children's questions/comments/problems. Although initially it was difficult to decide what data was important and what was not, a period referred to by Lofland (1995) as 'mucking about', over time the focus of the observations began to narrow as common themes were identified and explored in greater detail. Observations and informal conversations gave me the opportunity to understand the children in relation to a child's level of maturation, predispositions and familial influences, which in turn enabled me to better understand children's voices and meanings of health. Critically, it also gave me insight into how those voices were both mediated by the actions of practitioners and constituted by wider health discourse.

\section{Activity based tasks}


In line with the Mosaic approach, these tasks took the form of posters and a nursery tour which included photos of where children did physical activity. These methods are discussed in detail later in the paper.

The cohort of participants in this study were a vulnerable group (EAC, 2006), based on their age. As such, ethical issues were of concern when planning and carrying out the collection of data. Three ethical issues were of particular focus; (i) informed consent; (ii) power relations, and (iii) confidentiality. Whilst these issues are not unique to researching with children, they present different and sometimes significant challenges for the researcher (Mauthner, 1997; Thomas and O'Kane, 1998). Challenges relating to each of these issues were, indeed, experienced throughout the research.

Consent is often grounded in the assumption that the presentation of adequate information allows participants to 'understand' what they are being asked to do and is sufficient for them to make an informed decision to consent or not (David, Edwards and Alldred, 2001). However, seeking informed consent is an on-going process (Flewitt, 2005; Hill 2005) and is often far more difficult to gain from children. To be informed a child must, after all, first understand the nature of the study (what is expected of them and what the study involves) and this may be a problem if the child has no experience of what research is, or what the research entails (Greene and Hogan, 2005). For example, if a child is not familiar with what an interview is, how can he/she be expected to give informed consent to participate in one? Furthermore, children, like adults, need (and have a right) to know and understand how any data collected (verbal, visual, etc.) will be used.

It has been suggested (Davis and Watson, 2000) that, ideally, consent should be obtained from a child in person following the presentation of written or verbal information about the research. Previous research has illustrated that this can be achieved even with pre-school children (see Fine and Sandstorm, 1988) albeit with the explanation of the research having been simplified to its limits (for example; 'the researcher is going to play with and watch you and your friends to see what you do in nursery’). The National Children's Bureau (NBC) (Greene and Hogan, 2005) argues that extra care must be taken to ensure that all children participating have given 'consent' and understand the nature of the study. In contrast, the Society for Research in Child Development (2007) accepts that 'assent' by the child rather than 'consent' may be sufficient. For the purposes of this study, participants (aged three to five) gave 'assent' and parents gave informed 'consent' before partaking in the study. Assent meant helping children understand the purpose of the research and gaining their willingness to participate before any data was collected. Assent was gained from the children rather than consent because, after discussions with practitioners, it was acknowledged that the children would not (either legally or intellectually) be able to give 'consent' due to their age and stage of development. Therefore, prior to engaging in conversations with the participants, I choose to ask them for their assent by using either a happy or sad stamp to signify if they wanted to talk to me, emphasising that it was ok if they choose the sad stamp.

There were two phases to the study. The first focused on how different research methods could be used in each setting to collect 'rich data', while the second utilised some of the 
research methods which were successful to gain further data. This paper focuses on the first phase of the data collection and will critically reflect on the lessons learnt.

\section{Identifying Challenges}

Issues such as ethics, voice and engagement were important factors when choosing methods and the mosaic approach was used specifically to engage with and address these issues. However, as it transpired, these were not the most difficult issues to deal with, rather, the more pertinent ones related to interpretation - of meaning and understanding, of credibility and authenticity - what voice was I hearing, whose voice was speaking, why and to what purpose?

This research sought to seek the voices, views and understandings of children not adults. Central to this, was the need to acknowledge that children's ideas can be different in relation to the role of adults - often there is explicit success criteria that children are aware of and adhere to, to be seen as competent by adults, particularly in an education context. Pedagogic social contexts are always defined by specific power and control relations between subjects, discourses and agencies/spaces (Bernstein, 1977). Therefore, it was imperative for the researcher to find legitimate and authentic ways to listen to children's voices (Clark, 2007) unmediated by more powerful others. The role of the adult in such research with children is to provide space in which the child's voice is taken into serious consideration and to find a position from which to give it strength (Kupfer, 2011). Participation of children in this interplay of voice represents one way of advocating for children's views and opinions to be heard in a broader context. However, concerns such as these were not concerns the children shared. They were simply not interested in being 'given space to talk'. Rather, they were content to articulate their experiences, almost oblivious to me, essentially through play. Moreover, for young children such as these, play is how they learn and consequently, often how they articulate themselves (Siraj-Blatchford and Sylva, 2004; Wood and Altfield, 2005). From a methodological and theoretical perspective, then, children give expression to their understandings of the world through their age and stage of development. For example, when asked what they thought 'healthy' was, several children choose to physically demonstrate playing, running around or 'going to the gym'.

Field notes at $B B B$ :

Amy was wandering around the play area on her own. I decided to ask her what she thought the word healthy meant. She showed me what she learnt at gymnastics and how she could do forward rolls and star jumps.

Chloe saw this and came over to ask what we were doing. Amy said she was showing me her gymnastics because it was healthy.

Chloe stood with her arms flexed "going to the gym is healthy, it makes you muscly like daddy, he goes to the gym". 
Contrastingly, when I tried to engage other children across the settings in a conversation about health, they simply walked away. Does this mean they did not understand 'health' or was it just that they chose not to answer the question?

Some children are profoundly egocentric, but all are partly 'determined' by their level of development (psychological and physical) and primary socialisation, i.e. the values and attitudes of their family, culture and home. Given these complexities and the embodied voices (how children portray and see themselves in relation to their social world and others) of these young children, how as a researcher should I go about registering and reading these voices?

\section{Methods Trialled}

\section{Tours and Photographs}

At Busy Buzzy Bees, of interest was the nursery tour. With the use of child friendly 'VTech Kidizoon' video recorders and cameras, I asked two children at a time to take me on a tour showing me their favourite areas and where they did physical activity/exercises. It is acknowledged that using the terms physical activity/exercises could shape the children's responses and these terms were used because they were used by practitioners in each of the settings to describe when the children were engaged in 'structured', practitioner led physical exertion and therefore, I felt the children would be familiar with these terms rather than using others. Whilst initially children appeared distracted by the cameras and more interested in playing with them than taking part in the task, after a while, the initial excitement wore off and the cameras seemed to focus some of the children's attention on physical activity and showing me where they ran, jumped and played. This provided insight into children's perspectives on nursery and captured conversations and movements that other methods may not have been able to. For example, at Busy Buzzy Bees, children believed physical activity could only take place outside in the playground because that is where their bikes and hoops were, despite the fact they often did physical activity in the form of dance indoors. However, getting beyond capturing one moment in time, developing an understanding of what young children saw as physical activity in EYE, and how this linked to health was not easy. Normally photo elicitation is followed up with focus groups or interviews (e.g. Azzarito and Kirk, 2013; Azzarito and Hill 2013), however, across the EYE settings, practitioners (gatekeepers) restricted the use of such methods because they were not comfortable with the use of videos or cameras in the nursery setting. Trialling the camera demonstrated to the researcher, that there are several disadvantages to using still photography; it only captures one moment in time and there are potentially multiple interpretations of any one picture. However, it also revealed the benefits of getting children to use cameras to capture their view of the EYE setting, if the cameras are (i) introduced over several weeks to overcome initial excitement; (ii) used in conjunction with a more structured task; and (iii) used with one child at a time (initially anyway). In addition, a video camera was used to capture the tour and, again, whilst initially some children were either nervous or over excited in front of the 
camera, it provided insight into children's perspectives on nursery and captured conversations/movement other methods may not have been able to achieve. It suggested that the video camera can be an appropriate method to collect information on children's use of space and language.

\section{Poster Making}

During my initial visits to Little Stars, I engaged the children in some tasks to establish useful data collection techniques. The first task, poster making, involved the children being asked to cut out images of people being active. The children, for the most part, clearly understood the task and what it meant to be active. They selected a range of pictures (e.g. people hula hooping, people playing football, animals flying) and when asked why they had selected that picture, could explain how the person/animal was being active. There were however, language issues in this setting where some children either did not understand the task or were disinterested. These issues were dealt with by drawing on the expertise of Davinder, a practitioner who spoke Bengali, which for some of the children, was their first language and was therefore able to translate the task for them. However, at Little People, the method was not as useful as here practitioners suggested that their children would not understand the issue of health and did not normally 'do posters' so this activity would not work. This was, therefore, a more difficult issue to negotiate - how as a researcher in a relatively new context could I address these assumptions and how could I get young children to participate in an activity they were not used to, or broach a concept, 'health', they putatively would not understand? Pragmatically I chose to listen to the practitioners and put aside poster making until I had a better understanding of how the setting operated. In time, it became apparent to me through observations, that as most children choose to play outside rather than indoors, setting up such an activity would not be something the children would choose to engage in anyway. I therefore opted for other methods. MacPhail and Kinchin (2004) suggest there are several strengths to using drawings and poster making tasks with children, for example, it's fun, interactive; children unable/unwilling to participate in interviews can have the opportunity to express their views; and children can freely choose what to include without being limited by the researcher's frame of reference. However, although in some cases the strengths outlined by MacPhail and Kinchin (2004) were evident, with the younger children, their engagement with posters and drawings, was often restricted either by their limited opportunity, or ability, to select, cut and stick the pictures onto their posters - i.e., the wait time for glue or scissors often meant the younger children became uninterested and/or in some cases their physical development meant they struggled to use the scissors without adult help. In effect, their stage of maturation prohibited the use of certain mosaic methods.

The discussion above raises several pertinent issues relating to meaning making and understanding in relation to access granted to the researcher by the gatekeepers (practitioners). Within EYE settings, although invisible pedagogies ${ }^{\mathrm{ii}}$ are often dominant, social control remains with the practitioners. Invisible pedagogies promote implicit social hierarchies which reduce the control teachers (are perceived to) have over a learning activity and transfer it to the children. Control, however, is still maintained through the "process of inter-personal communication” (Bernstein, 1977, p. 520) and with the practitioner acting as a 
facilitator. Therefore, it was the practitioners who determined who was deemed 'able' and capable of speaking to the researcher and of offering an opinion on health. For example, within Little People, practitioners highlighted a group of four girls - two of whom were older than the other children - as the only children who might know or understand health. During an informal conversation with the room leader, I asked if she would be ok with me carrying out a poster making activity focused on health, she responded, “our children don't understand health and we don't do specific activities with them so you won't be able to ask them questions or (offer) pictures about health, they just won't be able to do it”. Similarly, at Busy Buzzy Bees when talking about health with children using pictures, Alice (practitioner) selected the children to take part in the discussions based on her own, rather than the children's, understandings of health behaviour: "these children like to talk and do lots of sport outside of nursery, parents are very active so they will be able to answer your questions”. While at Little Stars, the deputy manager Mrs Robinson identified and selected five boys because "they love to be creative and do posters, they are really into Power Rangers, always running around pretending to be them”.

Access to children and therefore the understandings I gathered was, then, determined largely by practitioners and their assessment of who they believed would be best able to answer questions and complete the research (poster) activity. These assessments were grounded in assumptions about children's home lives and access to (legitimate) health discourse outside of EYE. These were children who they thought could best represent them and the EYE setting - by giving (what they hoped would be) the best/ideal response to the researcher's questions about health.

The understandings practitioners had of children were, then, not arbitrary, but rather reflected their assumptions about social class, culture, family background, opportunity and access to knowledge, and the impact of these influences upon children beyond the EYE setting. Displaying positive attributes, consistent with practitioner expectations, for example, tidying up toys, sharing, or displaying 'manners' at snack and lunch were perceived as evidence of a child's ability to recognise and realise in situ instructional and regulative rules that were deemed to have significance beyond the EYE context within formal education and wider society. Critically, they were considered manifest evidence of 'good parenting', positive wider family influences, and investments in play. In terms of health knowledge, practitioners selected children who they perceived had the 'ability' to display 'appropriate' health knowledge to the researcher, to participate in the activities/data generation. Within these three EYE settings, learning and therefore health discourse was inextricably linked to practitioners' perceptions of children's home learning environment and parental influence, and not just their age/stage of development. Such assumptions influenced their view of children and what they could/could not understand should or should not know, in relation to health discourse (also see McEvilly et al, 2015). The mosaic approach I was using to ensure that I was listening to the children provided very little help in registering and acknowledging these insider (practitioner assumptions) / outsider (class and cultural) EYE influences and the impact they had on access to the full range of children capable of taking part in the research.

\section{What children say about health}


Aside from the issue of accessing children beyond those deemed 'able', issues arose around what children themselves said about health and how as a researcher I understood this. Early Years Foundation Stage (EYFS) policy has undoubtedly helped position EYE settings as key sites for addressing health issues wherein children are taught from an early age 'the importance for good health of physical activity and a healthy diet' (DfE, 2014, p. 8). For example, EYFS policy stipulates that providers should provide healthy meals (DfE, 2014, p26 3.47 and 3.48), although little information is given as to what 'healthy' means. EYFS policy practitioners are then expected to nurture a healthy individual, essentially through play, in accordance with the expectations of the EYFS. On one level, then, health discourses were a constant in children's lives. Across the three settings, pictures on walls, snacks on the tables assembled in relation to other discourses, were aimed at developing the 'independent [healthy] child' invoked and imagined by the EYFS policy texts (see DfE, 2104, p.26). Health within each setting was, then, part of the fabric, built into the setting so that it could be caught subconsciously rather than explicitly taught to the children. Therefore, how do children articulate what health is when they are rarely told about it explicitly? How would mosaic methods help me broach this issue? This challenge was particularly prominent within two of the three settings.

At Little Stars, for example, Mrs Hunter (practitioner) commented:

"We encourage them to eat healthy at snack time, we take the opportunity at the snack bar to talk to them, it's difficult when it is not their culture at home” (Mrs Hunter)

Similarly, at Little People, practitioners rarely talked to children either about eating 'healthy foods' or exercise. They believed that healthy eating was not something that was promoted at home. Stacey, a practitioner at Little People, for example, suggested;

"We try to after dinner, we will ask what the children have had, with McDonalds just at the corner, lots of them have that, some are still eating it when they come in... it's quick and easy for parents! We don’t say McDonalds is bad but we try to tell them other things are better. But it's hard, sometimes it depends on the child and what the parents let them eat. I suppose it’s hard to understand healthy.”

Cale et al (2016) suggest that older children (14-15years old) struggle to comprehend and articulate their understandings of health and often have reductive views of it, so how are much younger children supposed to articulate their understandings of health and how are we as researchers able to access and understand them? Adopting some aspects of the mosaic approach (i.e. nursery tour, video cameras, poster making) provided in most cases an initial starting point for engaging young children in discussions of health, but due to the 'invisible' nature of learning and the focus on play within the EYE settings, often behavioural indices (for example, children physically demonstrating health) alongside linguistic ones were needed to register children's understandings of health. For example, across all three settings, children often choose to both physically demonstrate and verbally state, what they understood as physical activity or which foods they saw as being healthy:

Field notes: 
At Busy Buzzy Bees, the children are having snack time. Some of the boys turn around and ask me what I am doing sat in the corner. I responded, 'I am looking at what goes on at nursery, what are you boys doing?' they responded 'eating, its snack time'. I then asked, 'what foods do you think are healthy food?' several boys spoke at once but then James stood up on his knees on the chair and said:

James: 'I'm going 'Little Ninjas' today, (he gets into a karate pose) I need to eat this fruit don’t I, so do exercises?”

Tom also jumped up out of his chair and began to run around the room "I eat bananas so I can run really really really really fast”.

Similarly, when asking children at Little People about healthy foods, several of them choose to demonstrate what was healthy using their bodies.

Field notes:

During free time, a group of girls were sat on the drawing table; I joined them and began to draw different foods (banana, apple, crisps, chocolate, and doughnut). Clara asked what I was drawing and why. I said I was drawing different foods and then asked which food was her favourite from the picture:

Clara: Bananas.

Researcher: I like bananas too. What about these foods? What do you like best? (pointing to the crisps, chocolate and doughnut)

Clara: crisps

Researcher: Which of these pictures do you think would be healthy for you to eat? Which of those things would be healthy?

Clara: Bananas! (as she jumps up tensing her arm to show me her muscles)

Asking children questions after they had chosen to initiate conversation with me, was a more useful way of engaging children in discussion, as many of them felt more comfortable or at least more willing to engage with my questions this way. However, this process, relied in the positive relationships and trust I had built with the children, during my time in each setting. It took time for the children to feel comfortable enough to talk and engage with me. Furthermore, most of the children chose to express their opinions and knowledge not just verbally but through their bodies -in the form of actions, poses or gestures to add meaning and clarity to their responses. However, expressed, children's understandings were neither arbitrary nor divorced from practitioner or wider discourses defining health, and both are equally reductive, as we will see below.

\section{Researcher Impact}


Given that I set out to ensure that the voices of young children, rather than those of gatekeepers and other adults, were captured by the research process it was imperative that I acknowledged my own role in the data collection process. Many researchers (Padgett, 2008; Hamzeh and Oliver, 2010) have suggested that a researcher's personal characteristics such as gender, race, age, linguistic style, dress code and demeanour can impact the way participants respond and share their experiences. I am a 'white' middle class, able-bodied female and as such fitted in with other practitioners who were, apart from two, white, able-bodied and female. I am a qualified secondary school Physical Education (PE) teacher but have worked with pre-school children in a football/sports context. My personal background and interests in $\mathrm{PE}$ and health generated my eagerness to conduct the research and helped shape the types of questions I asked and the conversations I engaged in with the children. My own belief that health and physical activity/education are important in children's development and learning prompted what I looked for in each setting.

These aspects undoubtedly impacted on what I investigated, how I did this and how I interpreted the data. For example, on several occasions whilst 'helping' and supervising the children across two of the three settings, I observed what I deemed inappropriate behaviour whether that be children fighting with each other or not displaying 'kind hands' as the nursery encouraged. During such occasions, as a researcher I faced an ethical dilemma, as a former teacher, I wanted to speak to the children and explain how their behaviour was unkind and how we should be nice to our friends. At the same time, however, I wanted to retain my persona and role as the researcher not another member of staff; for fear that the children may not be as open or honest if they came to view me in such a capacity. Initially, I chose to mention such behaviour to staff in passing in the hope they would deal with it and to reduce the sense of 'teacher guilt' I felt in not addressing the poor behaviour. However, one more challenging situation arose when a 3-year-old boy swore at another child: 'fuck you, I don't like you' and move as if to kick the other child while playing in the soft play area. Instinctively I suggested to the boy this language was not appropriate and moved to check the other child was ok. Shocked and surprised by this incident I spoke to the room leader but immediately felt that whilst ethically I had done the right thing, as a researcher, I had overstepped the boundaries and put at risk children seeing me as a passive observer of preschool life, rather than as an authoritative, controlling figure. The difficultly of judging the boundaries between how we should behave as researchers and how we should behave as responsible citizens has long troubled qualitative researchers, from the early days of Chicago school ethnography with street gangs and drug dealers (Venkatesh 1997) to those more recently documenting life behind the bicycle shed or deviancy inside schools (Allen, 2013). It has led Etherington to claim that, ethically reflective research 'requires us to come from behind the protective barrier of objectivity and invite others to join with us in our explanation of being a researcher and being human' (2007, p.615). Due to the age of the children and the 'duty of care' I felt towards the participants, I considered I had no choice but to act on the incident. The books and journals I had read on the mosaic approach had not provided me with guidance on how to deal with such a situation and I spent time during my data collection wondering if how I dealt with this incident would negatively impact on my research aims and data collection process. There was undoubtedly a cost to my intervention, to my quest to give 
each child a voice. The boy I had reprimanded was reluctant to speak to me for the rest of my time in the setting. However, more positively, my actions had encouraged other children to engage with me, initially to tell me if someone was misbehaving. Over time, these initial interactions allowed me to build a rapport with the children and allowed them to see me as more than an authoritative figure.

\section{Concluding reflections ... lessons learnt}

This reflexive account set out to explore how I could better understand children's voices through the fog of me the researcher, practitioners' and their subjectivity as well as the different research methods utilised. The paper has begun to highlight some of the challenges faced, how they were dealt with and the usefulness of adopting certain methods when researching socially and culturally different educational settings. Different research methodologies provide different claims for the status of knowledge produced. Historically, ethnographies (e.g. Willis, 1977; Fine, 1991; Yon, 2000) have provided rich, in depth descriptions of ethnographic moments in schools. I therefore adopted ethnographic methods to provide what I hoped would be a detailed and nuanced account of the experiences of young children in EYE and explore their embodiment and corporeality. Fitzpatrick (2013) argues that a key challenge for ethnographers is to balance issues of culture and identity with social hierarchies and structures. Ethnographic approaches do provide a means for representing children's voices and experiences, however, for me it was a challenge to capture and convey the complexities, fluidity and nature of children's interactions and transactions. This was largely because EYE settings do not conform to the highly-structured organisation that features in schools, children do not focus on one activity for any length of time, and they do not straightforwardly (linguistically) articulate their understandings of health.

But perhaps the most important point to emphasise here is that the data collection and meaning making process is neither arbitrary nor ever completely in the researcher's control. Rather, it is strongly influenced by the context of each setting; the social context of the respective communities of practice (peers, family and culture) and the access given to interaction with significant adults during data collection. Each of these impacted the data collection and the meanings constructed and conveyed by the children. The mosaic approach is undoubtedly a 'child-friendly' means of data collection enabling the researcher to access children's voices; however, it has its limitations. Whilst useful, several issues arose (relating to gatekeepers; my own positioning; wider social/cultural contexts) which influenced children's meaning making and my interpretation of the data. I had to acknowledge that mosaic methodology was too narrow a data collection method and its use alone was distorting the focus of my analysis. More time spent on poster making/drawing might have allowed me to unpick the children's understandings of health further, but this was not possible in two of the three settings for reasons beyond the researcher's control.

If nothing more the approach adopted in this research and the challenges identified highlight the importance of researchers interrogating their own assumptions and positionality and 
assessing how these influence choices made, methods used and interpretations of data. The paper raises the question of 'whose voice are we hearing' in and through the research process and despite using methods that claim to allow children's voices to be heard, the question remains. Children's voices are always mediated through others, whether the researcher or practitioner, and this paper has tried modestly to acknowledge and account for this process. 
References

Allen, L., (2013)., Behind the bike sheds: sexual geographies of schooling. British Journal of Sociology of Education 34(1): 56-75

Azzarito, L., and Kirk, D., (2013). Pedagogies, physical culture, and visual methods. London: Routledge

Azzarito, L., and Hill, J., (2013). Girls looking for a 'second home': bodies, difference and places of inclusion. Physical Education and Sport Pedagogy, 18 (4): 351-375

Bernstein, B. (1977). Class, Codes and Control, Vol 3, Towards a Theory of Educational Transmissions, 2nd revised ed, London: Routledge and Kegan Paul

Bogdan, R. and Taylor, S.J., 1975. Introduction to qualitative methods: A phenomenological approach to the social sciences. Chichester: John Wiley and Sons Inc.

Braun, A., Maguire, M., and Ball, S. (2010). Policy enactments in the UK secondary school: examining policy, practice and school positioning, Journal of Education Policy, 25 (4): 547560

Braun, A., Ball, S. and Maguire, M., (2011). Policy enactments in schools introduction: towards a toolbox for theory and research, Discourse: Studies in the Cultural Politics of Education, 32 (4): 581-583

Cale, L., Harris, J., Duncombe, R., and Musson, H. (2016). Promoting physical activity in secondary schools: Growing expectations, 'same old' issues? European Journal of Physical Education, 1-19.

Cale, L., Harris, J., and Chen, M. H., (2012). Monitoring health, activity and fitness in physical education: its current and future state of health. Sport, Education and Society 19(4):376-397

Christensen, P., and James, A., (2008) (Eds.), Research with children; perspectives and practice, London: Falmer second edition.

Clark A (2007) A hundred ways of listening: gathering children's perspectives of their early childhood environment. Young Children 62(3): 76-81.

Clark, A., and Moss, P., (2001). Listening to Young Children: The Mosaic Approach. London: National Children’s Bureau. 
Clark, A. and Moss, P. (2005). Spaces to play: more listening to young children using the Mosaic approach, London: National Children’s Bureau.

Clark, A., Kjorholt, A., and Moss, P., (2005) (Eds). Beyond Listening: Children's Perspectives on Early Childhood Services. Bristol: Policy Press

Cobb, C., Danby, S., and Farrell, A., (2005). 'Governance of children’s everyday spaces'. Australian Journal of Early Childhood 30(1): 14-20.

David, M., Edward, R., and Allred, P., (2001). Children and School-based Research: 'informed consent' or 'educated consent'? British Educational Research Journal 27(3): 347365

De Winter, M., Baeveldt, C. and Kooistra, J. (1999). 'Enabling Children: Participation as a New Perspective on Child-Health Promotion', Child Care, Health and Development 25(1): $15-25$.

DfE, (2014) Early Years Foundation Stage/Curriculum https://www.gov.uk/government/uploads/system/uploads/attachment_data/file/335504/EYFS _framework_from_1_September_2014_with_clarification_note.pdf

Dockett, S. and Perry, B. (2003). ‘Children's Views and Children's Voices in Starting School', Australian Journal of Early Childhood 28(1): 12-17.

Evans, J., Davies, B., \& Rich, E., (2009) The body made flesh: embodied learning and the corporeal device, British Journal of Sociology of Education, 30:4, 391-406

Evans, J., and Davies, B., (2011). New directions, new questions? Social theory, education and embodiment. Sport, Education and Society, 16(3): 263-278

Ely, M., (1991). Doing qualitative research: Circles within circles. London: Routledge Etherington, K., (2007). Ethical Research in Reflexive Relationships. Qualitative Inquiry 13(5): 599-616

Fine, M., (1991). Framing dropouts: notes on the politics of an urban public high school, New York: State University of New York Press 
Fine, G., and Sandstrom, K., (1988). Knowing children: Participant observation with minors. Qualitative Research Methods 15. Newbury Park: Sage.

Fitzpatrick, K., (2013). Why Critical Ethnography? Counterpoints: Critical Pedagogy, Physical Education and Urban Schooling, 432: 25-52

Flewitt, R., (2005). 'Conducting research with young children: some ethical considerations' Early Child Development and Care 175 (6): 553-565.

Greene, S., and Hogan, M., (2005). Researching children's experiences: methods and methodological issues, in Greene, S., and Hogan, M., (Ed) Researching Children's Experience: Approaches and Methods, London: Sage

Hamzeh., M., and Oliver. K., (2010). Gaining research access into the lives of Muslim girls: researchers negotiating muslimness, modesty, inshallah, and haram. International Journal of Qualitative Studies in Education 23(2): 165-180.

Hemming, P., and Madge, N., (2011). Researching children, youth and religion: Identity, complexity and agency. Childhood 19(1): 38-51

Hill, M. (2005). 'Ethical considerations in researching children’s experiences'. Chapter four, in Greene, S., and Hogan, D., (2006). (Eds.) Researching Children's Experience: Approaches and Methods, London: Sage

James, A., and Prout, A., (2015) (Eds) Constructing and reconstructing childhood: Contemporary issues in the sociological study of childhood, London: Routledge

Kacen, L., and Chaitin, J., (2006) The times are a changing: understanding qualitative research in ambiguous, conflictual and changing contexts. Qualitative Report 11: 209-228

Kupfer, H., (2011) Children's voices in Early Childhood Settings' everyday concerts. Chapter 7 in Harcourt, D., Perry, B., and Waller, T., (2011) (Eds) Researching young children's perspectives. London: Routledge

Krane, V., and Baird, S., (2005). Using Ethnography in Applied Sport Psychology, Journal of Applied Sport Psychology, 17 (2): 87-107

Lancaster, Y. P., and Kirby. P, (2014). "Seen and Heard: Exploring Assumptions, Beliefs and Values Underpinning Young Children's Participation.” In Contemporary Issues in the Early Years. (6e), edited by Gillian Pugh and Bernadette Duffy, 91-108. London: Sage. 
Lofland, J., (1995). Analytical Ethnography: Features, Failings, and Futures. Journal of Contemporary Ethnography, 24 (1):30 - 67

Madison, D., (2005) Critical ethnography: Method, ethics, and performance. London: Sage

MacPhail, A., and Kinchin, G., (2004). The use of drawings as an evaluative tool: students' experiences of sport education. Physical Education and Sport Pedagogy 9(1): 87-108

McEvilly, N., Verheul, M., Atencio, M., and Jess, M., (2014). Physical education for health and wellbeing: a discursive analysis of Scottish physical education curricular documentation. Discourse: studies in the cultural politics of education 35(2): 278-293

McEvilly, N. (2015). Investigating the place and meaning of 'physical education' to preschool children: Methodological lessons from a research study. Sport, Education and Society, 20(3), 340-360

McEvilly, N., Verheul, M., \& Atencio, M. (2015). Physical education at preschools: The meaning of 'physical education' to practitioners at three preschool settings in Scotland. Physical Education and Sport Pedagogy, 20(2), 117-130

Mortimore, P. and Whitty, G. (1997). Can School Improvement Overcome the Effects of Disadvantage? London: Institute of Education

Padgett, D., (2008). Qualitative Methods in Social Work Research. Thousand Oaks, CA: Sage

Pang, B., Alfrey, L., and Varera, (2016). Young Chinese Australians' subjectivities of 'health’ and '(un)healthy bodies’. Sport, Education and Society 21(7): 1091-1108

Pink, S., (2011). From embodiment to emplacement: re-thinking competing bodies, senses and spatialities, Sport, Education and Society, 16 (3): 343-355

Quennerstedt, M., Öhman, J., and Öhman, M., (2011). Investigating learning in physical education—a transactional approach, Sport, Education and Society, 16 (2): 159-177

Sandbaek, M. (1999). 'Adult Images of Childhood and Research on Client Children', International Journal of Social Research Methodology 12(3): 191-202.

Schenker, K., (2016). Health(y) education in Health and Physical Education. Sport, Education and Society (online)

Siraj-Blatchford, I., and Sylva, K., (2004) Researching pedagogy in English preschools, British Educational Research Journal, 30 (5): 713-7 
Thomson, P., (2008). Children and Young People: voices in visual research, Introduction, In Thomson, P., (2008) (Eds.) Doing Visual Research with Children and Young People, London: Routledge

Venkatesh, S., (1997). The Social Organization of Street Gang Activity in an Urban Ghetto. American Journal of Sociology 103(1): 82-111

Willis, P., (1977). Learning to labor: how working-class kids get working class jobs. New York: Columbia University Press

Wood, E. and Attfield, J. (2005). Play, learning and the early childhood curriculum. London: Paul Chapman

Yon, D (2000). Elusive culture: schooling, race and identity in global times, New York: State University of New York Press

\footnotetext{
${ }^{\mathrm{i}}$ Within the UK, Government at the time of data collection, provided 15 hours free childcare to parents of children aged 3-4 years who meet the entitlement requirements. As of September 2017, this entitlement has been increased to 30hours for some members of society (DfE, 2017).

ii Bernstein's (1975) endeavour to characterise the modalities of education led him to introduce the notions of invisible and visible pedagogies, with the difference between the two relating to the manner in which knowledge is transmitted. Invisible pedagogies feature weak frames and weak classification. This reduces the teacher's overt authority and blurs the boundaries between every day and school knowledge.
} 